\title{
Mathematics support sessions for second-level students
}

\author{
Máire Donlon, School of Mathematical Sciences, Dublin City University, Ireland. Email: \\ maire.donlon5@mail.dcu.ie \\ Eabhnat Ní Fhloinn, School of Mathematical Sciences, Dublin City University, Ireland. Email: \\ eabhnat.nifhloinn@dcu.ie
}

\section{Abstract}

This paper reports on a free drop-in mathematics support service offered to secondary school students by Dublin City University. Pre-service mathematics teachers volunteered as tutors in the scheme, which was available to students from $1^{\text {st }}-6^{\text {th }}$ year. Both students and tutors were surveyed to ascertain the benefits of the scheme to all parties involved.

Keywords: Mathematics Learning Support

\section{Introduction}

It is well researched and documented that there is a problem with the level of mathematics students possess as they begin higher education. This results in low attainment rates in courses that require mathematics, and courses that involve mathematics modules. Many Higher Education Institutes (HEIs) have confronted this problem by offering mathematics support to students outside of the usual lectures and tutorials. This support can take many forms and aims to bridge the gap between the mathematics that they learned in school and the level of achievement that is required in college (O'Sullivan et al., 2014).

In 2015, Dublin City University (DCU) began providing mathematics support sessions for students aged from $12-18$ years old $\left(1^{\text {st }}-6^{\text {th }}\right.$ year in secondary school). This was an initiative set up by the Maths Learning Centre, in conjunction with the School Liaison Office, and the sessions were free for students to attend. The support sessions were modelled on the traditional format of mathematics support, where students bring their own questions, work on them either individually or in small groups, and ask the tutors for assistance if and when they encounter a problem. Sessions ran for two hours one evening per week, and most students attended for the full two hours. Students were assigned to classrooms according to their year groups. The ratio of students to tutors varied but was usually one tutor for six to eight students. Although an online booking system was used, there was usually some discrepancy between the number who signed up and the number of students who attended the sessions. The School Liaison Office in DCU sent letters to secondary schools in the locality to make them aware of the drop-in sessions, as well as posting the information on online noticeboards and sending emails to relevant mailing lists.

The volunteer tutors were DCU undergraduate pre-service mathematics teachers, mostly in $3^{\text {rd }}$ or $4^{\text {th }}$ year of their studies. There were between 10 and 15 tutors in any given week, with an average of 70-80 students attending. The sessions were run on a trial basis for six weeks before Christmas, and due to strongly positive feedback from all involved, ran for a further eight weeks from February - April 2016.

Some tutors were apprehensive about the wide variety of questions that could be posed in a single session, citing lack of familiarity with the curriculum and lack of confidence to teach while unprepared. To ease these fears, some general notes from mathcentre.ac.uk were provided to tutors to use with students if needed. Some students also struggled with the concept of drop-in mathematics support. Senior cycle students $\left(4^{\text {th }}-6^{\text {th }}\right.$ year $)$ adapted more quickly, and were more likely to work on different topics themselves, while junior cycle students worked on the same topic 
as those around them. As a result, fewer tutors were required to work with the junior cycle students, where peer teaching was also much more evident, although many reasons could account for that fact.

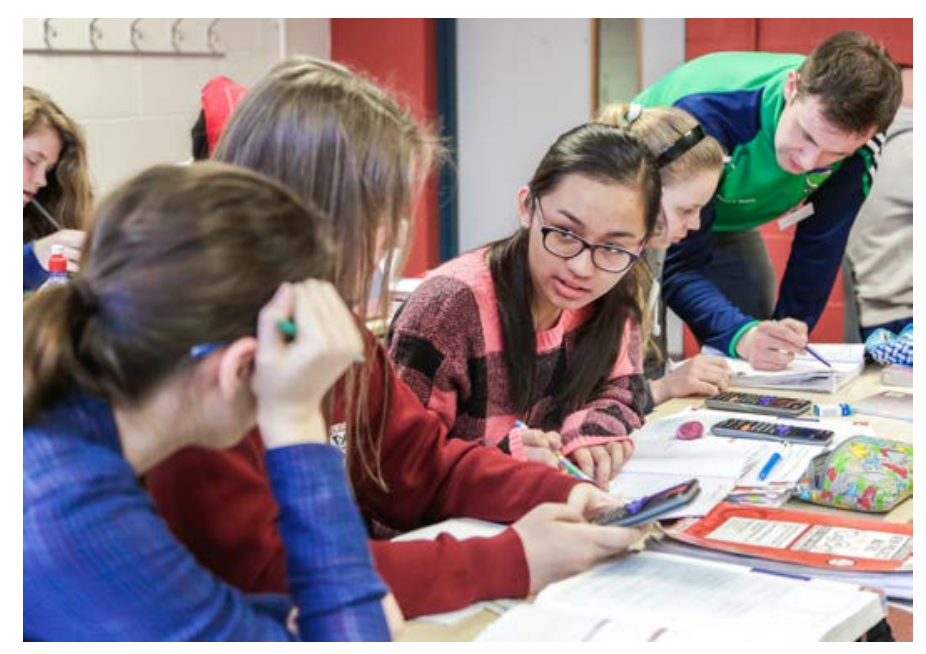

Figure 1. Students and tutors working during a second-level drop-in maths support session in DCU

\section{Literature Review}

Learning support in mathematics can be defined as "any facility or program providing extra optional assistance in mathematics and statistics for students during their enrolled study in a university degree program, with such assistance being outside the formally scheduled classes and activities for their enrolled course" (MacGillivray, 2009, p.457). As the principle idea behind maths support is the same whether at second or third level, the characteristics are similar. The essentials for any type of maths support include a quiet relaxed atmosphere, with maths staff to provide support. Peer learning should also be accommodated. Some programmes will include one-to-one and group tuition, which usually occur in an open plan area with plenty of desks and some books/notes available (Patel and Little, 2006). Gallimore and Stewart (2014) highlight that each individual student knows their level of achievement and where they are struggling. They argue that students "understand what they need to do to improve, and they know how to make that improvement" (p.101). Lacking confidence and mathematical fluency can be a major obstacle for students as they strive to succeed in their studies (MacGillivray, 2009), so it is important that all parties involved encourage students.

The impact on the volunteer tutors is important to consider. Ní Fhloinn (2010) demonstrated the positive impact on third level tutors mentoring second level maths students by visiting their school for an hour once a week and providing one-on-one help in mathematics. The tutors were happy to share their love of maths and a few considered becoming maths teachers as a result. Patel and Little (2006) also referred to this motivation behind tutors volunteering: seeing improvements in students who struggled with maths as a result of their coaching. Gallimore and Stewart (2014) highlighted the importance of tutor appreciation: those who received recognition for the work they did benefitted more than they would have from just taking part. Hrastinski et al. (2014) agreed that "the main driver of the coaches seem to be the desire to help students" (p.88).

As the tutors in question were pre-service teachers, this tutoring can be viewed as a further learning opportunity. Teaching is something that must be learned over time, and on-the-job training is essential (Tzur, 2010). This corresponds with the common view that teaching someone else is the best way to learn (Hrastinski et al., 2014; Webb, 1989). Patel and Little (2006) and Hrastinski et al. (2014) also show that in supportive environments, both student and tutor learning can occur. It 
can be beneficial for tutors to work as a team, as this allows for discussion and consultation between them. It removes the sense of isolation that tutors can sometimes experience if they are not working in a supportive environment (Hrastinski et al., 2014). However, a study conducted by Collins (2005 cited by Gallimore and Stewart, 2014) highlighted that some volunteer peer-tutors thought it took time away from their personal study.

A large number of institutions in Ireland offer revision courses or exam tutoring for second-level students. In recent years, these have also become available online through websites such as irishgrinds.com ("grind" is commonly used for private tuition in Ireland), tutorhub.ie and positivemaths.ie. Some HEls in Ireland offer types of mathematics support to second level students. For example, Maynooth University offer drop-in sessions, similar to those described in this paper (Maynooth University, 2016). In the Institute of Technology Tallaght, students work with pupils from local schools to support the development of their maths skills (Institute of Technology Tallaght, 2015). In University College Cork, students volunteer through UCC Plus+, providing homework clubs and extra revision sessions for examination years (University College Cork, 2016). Similar to the study conducted by Ní Fhloinn (2010), students in Dublin Institute of Technology also provided one-on-one maths support to second level students through a Voluntary Maths Tuition Programme (Dublin Institute of Technology, 2012).

\section{Methodology}

The aim of this research project was to determine how these sessions benefited both the students and the tutors. To carry out this investigation, surveys were given to both the students and the tutors. Students completed a paper-based survey during a drop-in session, while, for tutors, an online survey was conducted, using SurveyMonkey. The student surveys were completed in March 2016 and, in total, 97 students answered the survey. 20 tutors in total had volunteered at the support sessions over the two semesters, 15 of whom completed the survey.

In designing the surveys, surveys conducted by the university level mathematics learning support were consulted (O'Sullivan et al., 2014). This was used to get an idea of the types of questions that should be asked to get the best information from both students and tutors. It was observed from these surveys that closed questions, where respondents are given options to choose from, were the most popular. This was taken into account when both student and tutor surveys were designed.

\section{Results and Discussion}

\subsection{Student Survey}

The student responses were representative of those who attended, with about $60 \%$ from junior cycle $\left(1^{\text {st }}-3^{\text {rd }}\right.$ years $)$ and $40 \%$ senior cycle. A quarter had attended more than seven sessions, with 15 having attended between four and six sessions and the remainder between one and three sessions.

When students were asked to rank how much the sessions helped with their maths on a scale of 1 to 5 , with 1 being 'not at all' and 5 being 'a lot', their responses were positive, with $64 \%$ of students answering a 4 or 5 and a further $24 \%$ a more neutral 3 . When students were asked to rank how the sessions affected their confidence answering maths questions, with the same scale, 53\% answered 4 or 5 , with $33 \%$ answering a 3.

In response to a question asking "Do you like choosing the topic you work on in the sessions?" $90 \%$ of students replied positively. Reasons given included that they were able to work on topics with which they were struggling, and that they could revise topics for tests. Those who disagreed would have preferred structured classes. Overall, this showed that drop-in maths support was suitable for these students, in agreement with what was suggested by Gallimore and Stewart 
(2014): that students know the areas they need to work on, and what is required of them to make that improvement.

$82 \%$ said that tutors used different approaches to their teachers. This may be an indication that new methodologies have been introduced to pre-service teachers. Comments included that the tutors tried explaining things in different ways if they did not understand the first explanation. It must be noted that it is likely the tutors had more time than teachers to spend explaining topics, and some students mentioned this. Other students simply said that the tutors used language that was easier to understand. This was all positive feedback and supports the previous results which suggested that the students found the support sessions beneficial.

Students were asked if they participated in any maths activities outside of the classroom. Only $11 \%$ said yes, most of whom were in exam classes, getting individual tuition. Three students attended youth club maths classes.

Another question that generated interesting responses was "Why did you decide to take part in the maths tutoring?" The results are below in Figure 2. 41\% of students said they made the decision to come themselves. This supports the opinion of Gallimore and Stewart (2014) that students are aware of what they need to do to succeed. The same number of students said that their 'parents encouraged me to attend' as 'friends were going'. Interestingly, only $16 \%$ of students said that it was the teacher suggested they attend. As contacting schools was the primary way the sessions were advertised, it was expected that this number would be higher. However, it may have been that the teacher mentioned the sessions, but the students themselves made the decision to come. This also suggests that students were taking responsibility for their learning.

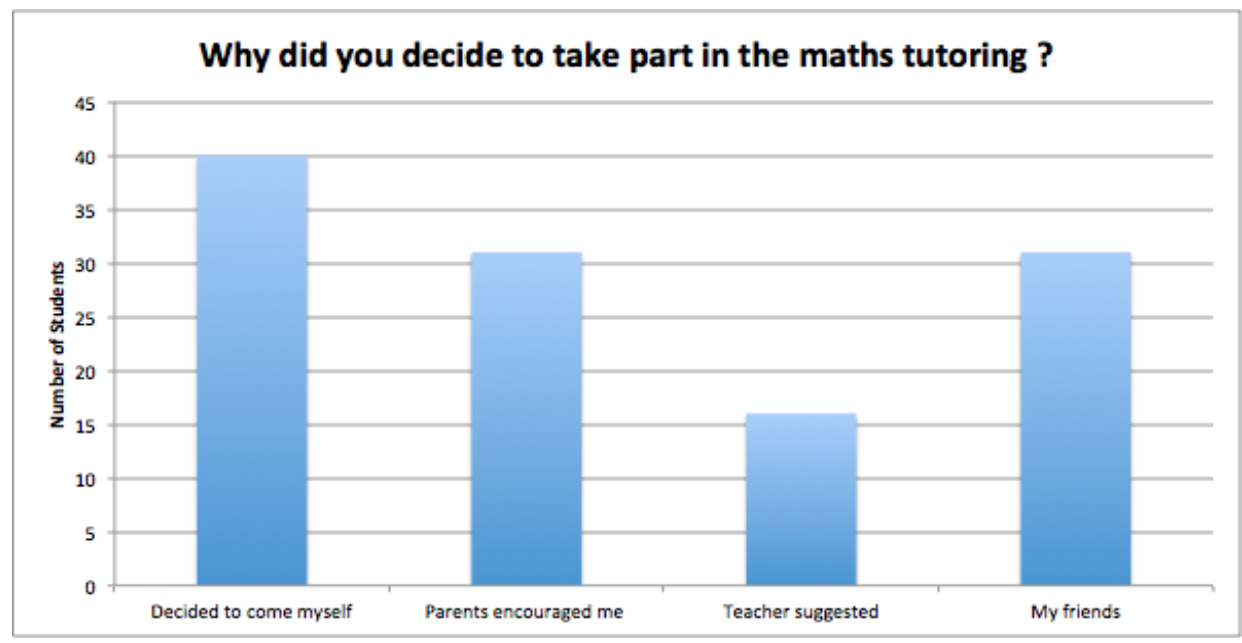

Figure 2. Student response to "Why did you decide to take part in the maths tutoring?"

Students were asked what it was about the sessions that they found useful. The results are displayed in Figure 3. Again, tutors featured highly in the responses with $64 \%$ of students saying that the helpful tutors were an important aspect of the sessions. 38\% said that they like that the sessions were a quiet place to do work. This was somewhat unexpected as the sessions were not designated quiet areas, and a certain amount of noise was expected. Patel \& Little (2006) also found that a quiet space was an important element for providing maths support. 


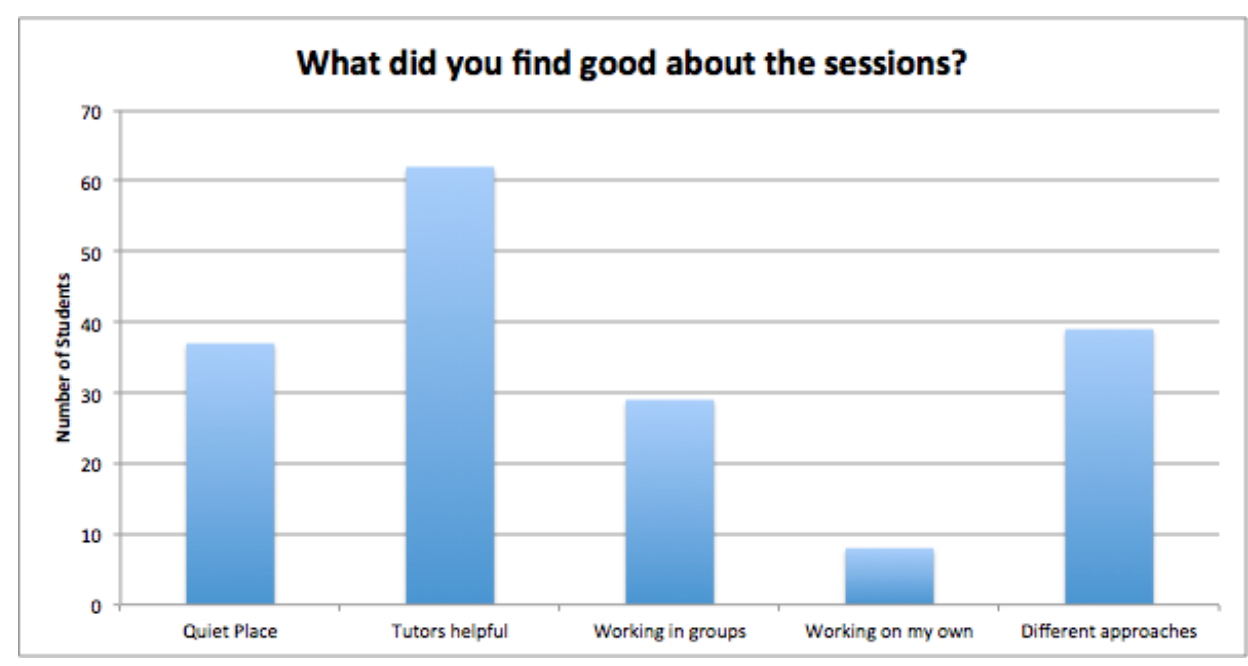

Figure 3. Student response to "What did you find good about the sessions?"

The overall feedback from the students was overwhelmingly positive. $90 \%$ of students said that they enjoyed attending the sessions, and $92 \%$ would recommend them to a friend or family member. Some students had already recommended them to friends and were now attending the sessions in groups.

\subsection{Tutor Survey}

The online tutor survey achieved a response rate of $75 \%$. All tutors were pre-service teachers studying mathematics teaching in DCU. $40 \%$ were $4^{\text {th }}$ year students, while $53 \%$ were in $3^{\text {rd }}$ year, and $7 \%$ in $2^{\text {nd }}$ year. Almost half of tutors who responded had volunteered more than 7 times. This result demonstrates the level of commitment involved for the tutors.

When tutors were asked why they initially volunteered, there were a number of interesting responses. Unsurprisingly, over $70 \%$ of tutors signed up to gain experience. It was anticipated that this would be a major reason behind the tutors volunteering. While pre-service teachers do complete long blocks of teaching placement, there is also a long time between placements where they do not have any interaction with students. The tutoring sessions allowed tutors to gain more experience dealing with students and their difficulties in between placements. One tutor volunteered "to help students with problems, also to gain experience in dealing with the questions I would not have been prepared for". A few other tutors mentioned that they "enjoy helping others with maths problems". This supports what Hrastinski et al. (2014) found, that the desire to help students is the main reason behind volunteering.

When tutors were asked if they would like to continue tutoring next year (for those in final year, if they would have liked to), $87 \%$ of students said that they would and most tutors would like the sessions to run for 8 weeks in each semester. The tutors also suggested that pre-service teachers in all years should participate. While this seems like a large commitment, the tutors generally suggested "it did not take up too much time". This contrasts with the findings of Gallimore and Stewart (2014), who reported that some tutors would not volunteer as it was too time consuming. However, it should be noted that their study involved peer-mentoring instead, and the cohort involved were not pre-service teachers, which likely had an impact upon their perception of how time-consuming such volunteering was.

To discover how exactly the volunteering experience benefited the tutors, a list of options was provided, and the results are displayed below in Figure 4. 


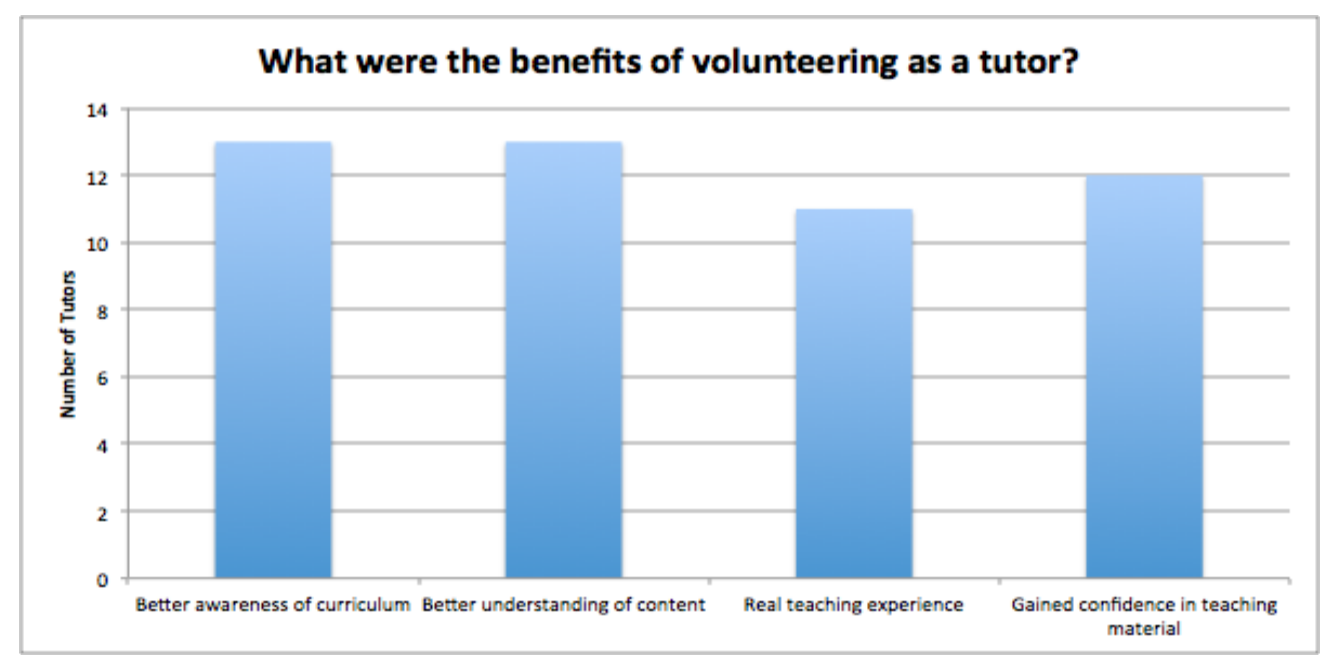

Figure 4. Student response to "What were the benefits of volunteering as a tutor?

In addition, a small number of tutors suggested other benefits. One stated "Developing different methods to help students understand content" which echoes comments from the student survey that tutors would use a variety of methods until they found the optimum approach. This supports the views of Tsur (2010), Hrastinski et al. (2014) and Webb (1989), that teaching is something that is learned from practice, and that the best way to learn something is by teaching. Another tutor stated "Feel better about myself" which supports Gallimore and Stewart (2014) who claimed that tutoring can result in an increase in tutor confidence. As pre-service teachers, the tutors had all been on teaching practice. This can be a difficult experience and can leave student teachers doubting their suitability for the job. In contrast, this experience seems to have had the opposite effect, and instead provided tutors with reassurance about their chosen career. The support sessions provided the tutors with an opportunity to practise interacting with students on a regular basis. The experience seemed to boost the tutors' confidence in their ability to deal with students and their misconceptions.

The fact that tutors were unable to prepare for the session also raised some concerns among the tutors themselves. While most teachers will experience some off-topic questions in their classroom, being unprepared for an entire class is a situation that teachers should avoid. Most tutors found it "daunting at first", and "difficult not knowing what type of question the student might ask". However, $60 \%$ said that it was a good situation for a teacher to be in; that the tutor "was seeing the question from a similar point of view as that of the student, in that we both didn't know straight away how to answer it and had to think about what the best plan of attack was". A number of tutors mentioned that they felt comfortable asking another tutor for help, and that it was beneficial for students to see that tutors work as teams. As one tutor mentioned, there was a relaxed environment where students were comfortable to ask for help, but importantly, so were tutors. This supports the theory proposed by Hrastinski et al. (2014) that tutors benefit from working in a supportive environment, allowing tutor learning to take place. Many tutors moved from initial anxiety about teaching unprepared to seeing a benefit from it. The mathcentre notes provided were used a small number of times in early sessions. However, as the sessions progressed and the tutors' confidence levels increased, they were no longer required.

When the tutors were asked if they believed their experience would benefit them in their future career, $100 \%$ responded "Yes". There appears to be a similar positive impact on the tutors in this study as that previously found by Ní Fhloinn (2010). Seven tutors said that it was the best way to revise "the content and the types of question asked", with two tutors also suggesting that they could set up something similar on a smaller scale in schools when they have qualified. A couple of 
tutors also mentioned that it would help when qualified when they need to provide students with "individual help for a couple of minutes while the rest of the class are working", while also saying that the sessions "helped to think on your feet and engage better with students." Being aware of student misconceptions before beginning their teaching careers is an advantage that should benefit them in applying for jobs.

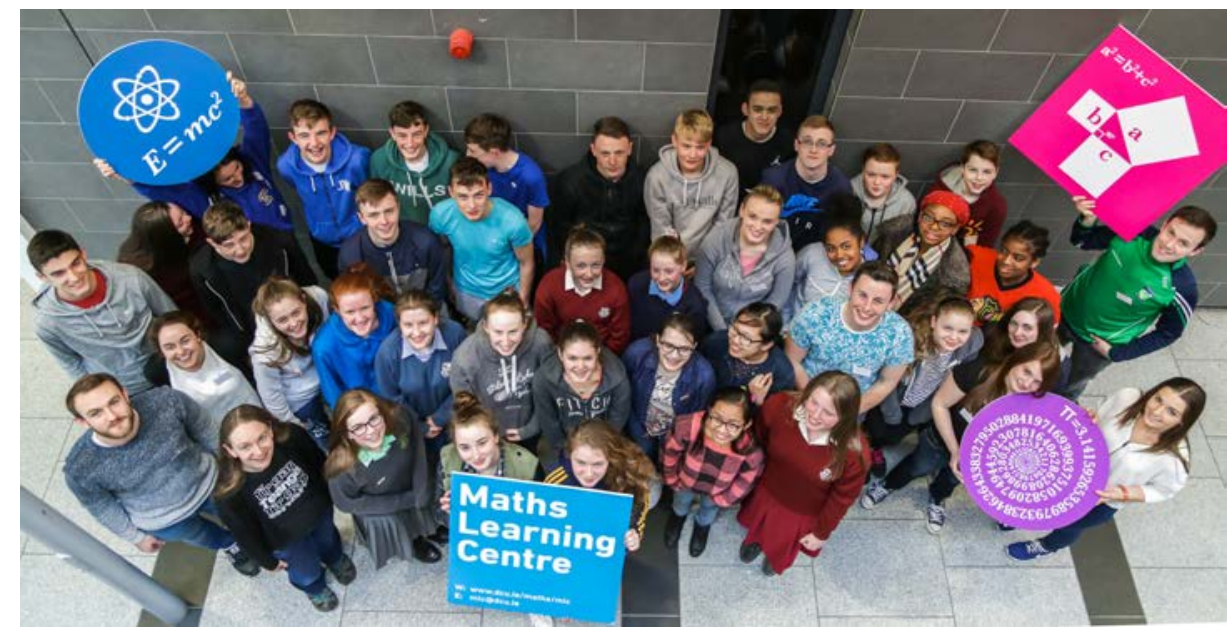

Figure 5. Some of the students and tutors who participated in the second-level drop-in maths support sessions in DCU

When asked if the sessions had provided reassurance that they wanted to be teachers, 93\% of tutors said that it did. This may provide the most concrete evidence that this is a programme that should be encouraged for all pre-service maths teachers. Comments also included the following: "Positive feedback was encouraging"; "I enjoyed helping them work things out"; and "I think it is good to help students, and students are always very grateful when you help." Here, again, the importance of the appreciation the tutors received is highlighted. It meant a lot to the tutors that their time and efforts were appreciated by the students. This was a reoccurring theme throughout the literature (Gallimore and Stewart 2014; Hrastinski et al., 2014), and also throughout this project.

When asked if the tutoring had any impact on their academic course, $87 \%$ said no, despite them having a full timetable of lectures while volunteering. Again, this contrasts with the findings of Gallimore and Stewart (2014), who dealt with a cohort of non-teachers involved in peer-mentoring. The tutors in our study were all very positive about the support sessions and also about maths in general. When asked for any final comments, they said: "It is worthwhile for those studying teaching to give them more experience when they are not on placement"; and "I have really enjoyed my experience as a volunteer tutor... We have an opportunity to help students and put our knowledge to some good use".

\section{Conclusion}

Through the questionnaires, it was established that there were many benefits for both the students and the tutors. The students benefitted as they felt their mathematical ability had improved and their confidence levels increased as a result of attending the sessions. The students responded well to the structure of the sessions. The students responded particularly well to the tutors and the methods they implemented. They liked that the drop-in sessions offered a quiet space for them to work independently or in small groups, with tutors available to assist them if help was required. 
While the support sessions were initially set up for the benefit of the students, it became clear that there were also many benefits for the tutors who volunteered, such as gaining more teaching experience. Tutors also reported that they benefitted from being exposed to the curriculum and became more familiar with the content being taught in schools. They felt they benefitted from working as part of a team in a relaxed learning environment, where it was possible for them to learn as well as the students. An unexpected benefit was that the tutoring experience provided reassurance for the tutors that they wanted to be teachers. The sessions offered a real environment for tutors to interact with students and to become familiar with common misconceptions. The feedback from the tutors was overwhelmingly positive, with most saying they would like to continue tutoring. Their participation in the sessions also led to increased confidence levels in their ability to teach and to deal with students' misconceptions.

\section{Acknowledgments}

The authors would like to acknowledge the contribution of Colette O'Beirne from DCU School Liaison Office to the second-level mathematics support drop-in initiative.

\section{References}

Dublin Institute of Technology, 2012. DIT Student Maths Tutors Making a Difference. Available at: http://www.dit.ie/ditfoundation/newsevents/news/archive/ditstudentmathstutorsmakingadifference [Accessed 25 April 2016].

Gallimore, M. and Stewart, J., 2014. Increasing the impact of mathematics support on aiding student transition in higher education. Teaching Mathematics and Its Applications. 33(1), pp.98109.

Hrastinski, S., Edman, A., Andersson, F., Kawnine, T. and Soames, C., 2014. Informal math coaching by instant messaging: Two case studies of how university students coach K-12 students, Interactive Learning Environments, 22(1), pp.84-96.

Institute of Technology Tallaght, 2015. President's Volunteer Programme (Maths). Available at: http://www.it-tallaght.ie/pvp [Accessed 26 April 2016].

MacGillivray, H., 2009. Learning support and students studying mathematics and statistics. International Journal of Mathematical Education in Science and Technology. 40(4), pp.455-472.

Maynooth University, 2016. Drop in Sessions for Second Level Students. Available at: http://supportcentre.maths.nuim.ie/secondlevel [Accessed 25 April 2016].

Ní Fhloinn, E., 2010. DCU Voluntary Maths Tuition Programme. DCU LIU: Teaching Reflections, pp.12-14.

O'Sullivan, C., Mac an Bhaird, C., Fitzmaurice, O. and Ní Fhloinn, E., 2014. An Irish Mathematics Learning Support Network Report on Student Evaluation of Mathematics Learning Support: Insights from a large scale multi-institutional survey. Limerick: NCE-MSTL, pp.18-20.

Patel, C. and Little, J., 2006. Measuring maths study support. Teaching Mathematics and Its Applications. 25(3), pp.131-138.

Tzur, R., 2010. How and What Might Teachers Learn Through Teaching Mathematics: Contributions to Closing an Unspoken Gap. In: Leiken R, and Zazkis, R Learning Through Teaching Mathematics. 5th ed. London: Springer, pp.49-68. 
University College Cork, 2016. Working with Schools - UCC PLUS+ Outreach Programme. Available at: https://www.ucc.ie/en/uccplus/schools [Accessed 25 April 2016].

Webb, N.M., 1989. Peer interaction and learning in small groups. International Journal of Educational Research, 13, pp.21-39. 